\title{
Communication Science Based Public Administration Course Content: DME Concept Mapping Approach
}

\author{
Michael Lindsay Hall \\ School of Justice Studies, Roger Williams University, Providence, US \\ Email address: \\ mhall@rwu.edu \\ To cite this article: \\ Michael Lindsay Hall. Communication Science Based Public Administration Course Content: DME Concept Mapping Approach. Science \\ Journal of Education. Vol. 6, No. 3, 2018, pp. 103-109. doi: 10.11648/j.sjedu.20180603.15
}

Received: June 26, 2018; Accepted: August 3, 2018; Published: October 9, 2018

\begin{abstract}
Faculty face a number of challenges in the classroom when delivering course material. The challenges include student ways of learning, student sense making of the material, and cognitive load in the minds of the students as they try to integrate the course with what they know and what they need to learn. An instructor's style is also a major ingredient in delivering course material. Communication science combined with Distance Magnitude Estimation (DME) can be a tool for faculty in working with these and other challenges. The article presents an actual DME based map and then illustrates how the map can be incorporated into building a course and refining its delivery. The article also shows how the DME map can add to assessment of student learning.
\end{abstract}

Keywords: Concept Mapping, Distance Magnitude Estimation, Communication Science, Faculty, Course Building, Course Delivery

\section{Introduction}

The complexities of teaching public administration cannot be underestimated. Naturally, these complexities are not limited to the public administration classroom. All higher education courses face them also. However, for purposes of illustration of the distance magnitude estimation (DME) approach to working through teaching in a complex environment public administration will be the discipline of focus.

The complexities in public administration begin with a significant history of practice and education [1] (Luton, 2002, p. 439). Public administration history and its educational basis are fully connected to the Progressive Movement of the late $19^{\text {th }}$ and beyond [2] . Since its beginnings in the Progressive Movement, public administration has added to its education with a body of research defined specifically as public administration and has encompassed a full array of other disciplines such as health care administration, sciences such as biology, other social sciences including sociology and anthropology, and even communication science. The public administration teaching faculty must engage students while drawing on all the multidisciplinary aspects of the field in order to teach sound policy and program decision making, sound budget decisions, sound communication skills, and create course content sufficient to achieve results in these areas. Here, then, is a beginning point of understanding classroom complexities but there are more complexities.

Gallagher [3] finds the classroom is complex because of the ways students work to learn. He says, "The classroom, with its complex social structure and kaleidoscope of cognitive and psycho-sociological variables, has not often been the object of serious research '. As a result of little, if any research, is fully extant. Gallagher goes on to write "the essence of teaching has remained a mystery and we often hear the statement that teaching is an art". Consequently, faculty rely on experience and personal style to conduct courses.

At some very crucial point in course delivery, an instructor will have to navigate the complexities of psycho-social variables by "blending", as Gallagher calls it, the instructor's style, background, experience, and course content knowledge to work with this kind of classroom complexity. The problem for the instructor is just what blend to use and how much of each factor to consider in course delivery.

Further adding to the blend is what Hayne and McDaniel [4] call roles the faculty member is called on to play in addition to instructor. Those roles include expert, trainer, and 
community organization speaker and representative of his or her university.

Certainly not the least of the psycho-social variables is what Jornet and Roth [5] call "sense making". Through the kaleidoscope of variables in the classroom, the faculty member must guide the students toward understanding and knowing the course content as they try to make sense of the classrooms presentations. According to Jornet and Roth, students do so by using their experience of representations of what the content means to them. Thus, the teacher must try to work through what students' experiences are with the presentation of concepts and lessons as students have encountered them.

\section{Cognitive Load}

Bulunuz and Jarret [6] observe "Students come to class with ideas about the natural world". For working students, in service or preservice, the observation of Prince, et al, is relevant to public administration courses. They write "Parttime graduate and undergraduate business education requires from students a protracted and arduous investment while balancing work and studies" (p. 208). Students must learn while carrying this kind of load, plus the load of previous experience, previous representations of course concepts, and the instructor's style. All of these factors combine to create cognitive load. Public administration adult learners are very similar in this regard.

Lee and Lang [7] find that dynamic cognitive load is a key factor in effectiveness of messages. Presentations for classes would be a form of messaging. Cognitive load has to do with how much conceptual space is taken up by a message combined with other affective states in the mind of the receiver. Understanding dynamic cognitive load in the message or presentation can lead to predictions about lecture or message impact. More simply put, cognitive load means how much a person can remember of a message while thinking about other life events and other information about the surrounding environment. The dynamics of a presentation as a message involve cognitive resources devoted to a message and the complexity of that message. Thus, the cognitive load of a message must have a trajectory to penetrate experience, psycho-social variables, and perceptions already in place in order for the presentation to deliver a sense-making experience. The cognitive load of any student would involve the kinds of complexities described earlier, maybe more so for working students who add family and work to their conceptual space.

Chung and Fink [8] say the "course" of the message trajectory, literally the movement of the message in the mind of the receiver of the message, must be developed for managing cognitive load. They report their research points to messages resulting in belief change if the messages have appropriate message order, properly positioned in the message, and have positive content. If such a trajectory is developed, a more crafted presentation to meet the challenges found in a classroom can be developed.
The use of the Chung and Fink and Lee and Lang concepts, would provide valuable lessons from communication science according to Niederdeppe, et al. [9]. They say with a deliberate effort to create effective messages greater awareness of important social problems such as the disparities in health among the poor across the globe can be crafted. The approach they describe, combined with knowledge of cognitive load and message trajectory research, offers an avenue for public administration classroom presentations to create awareness of its history, applications, research, and best practices. These issues would be particularly important in disciplines such as public administration, sociology, political science, among others.

Balancing all the important factors involved in delivering classroom presentations, projects, writing assignments, and the like, despite the challenges present in a classroom, can be met using communication science research. A teaching approach which combines existing faculty skills and knowledge using a strategy based in communication science can assist a faculty member in developing delivery of course content to navigate the complexities found in classrooms. The research approach begins with a tool called concept mapping.

\section{Concept Mapping}

William Trochim, et al, [10] was among the first to develop the idea of concept mapping. He has written that "Concept mapping combines a group process (brainstorming, unstructured sorting, and rating of the brainstormed items) with several multivariate statistical analyses (multidimensional scaling and hierarchical cluster analysis) and concludes with a group interpretation of the conceptual maps that result". Freeman and Jessup [11] report the usefulness of concept mapping is based in ease of use, benefits to the users of the approach and, importantly, for communication.

Woelfel and Fink, coming at concept mapping from a communication science approach, add distance magnitude estimation [12]. Hall [13] reports "distance magnitude estimation added to concept mapping" can provide mathematical data on important concepts which Trochim, et al, would call ideas. For Woelfel and Fink, those ideas are represented in a distance magnitude estimation (DME) multidimensional map to enhance the understanding of the ideas or concepts in cognitive space. One of those ideas, as the communication science and related literature reviewed above note, is of very primary importance: the presentation or message recipient. The depiction of the resulting DME concept map shows the important concepts in relation to the message recipient, known in such a map, as "you" or "self".

Trochim and Woelfel and Fink begin the concept mapping research with braining storming followed by sorting through unstructured statement data as a step would be what Woelfel and Fink would note as the attribute determining process. Additionally, as Trochim indicated, the subsequent DME map formed by these attributes is multidimensional. 
DME is one way of measuring supported by Newcombe [14] who asserts interacting with the world requires ability to understand magnitude. She provides an illustration of how magnitude is often used to interpret a map. She writes, "perceptual estimation-roughly a quarter away across on a map implies roughly a quarter of the way across on a referent space". Further, Eadie and Doyle [15] point out DME provides a measurement advantage since DME measurement avoids the systematic bias attributed to interval scales. The well-known interval perceptual scales require respondents attempting to react to those scales by using a "fixed predefined scale". The distance perceived between intervals is assumed to be uniform in weight, distance, and magnitude between numerical intervals and, thus, equal. No more information can be generated beyond that provided by the predetermined interval categories. Eadie and Doyle report that Stevens [16] asserts units of analysis do not perceive intervals as equal (Eadie and Doyle, 2002).

The research reported below follows DME measurement principles and communication science lessons. The approach yielded a multidimensional concept map from which presentation elements for classroom content were generated. According to Aydogan and Ergun [17], "A concept map is a two dimensional diagram in which concepts and the links between them are displayed graphically, showing their interconnected relationships under a wider concept heading." Ali an Ismail [18] draw on Novak and Gowin [19] to note that concept mapping follows Bloom's taxonomy. Kinchin, et al., offer concept mapping as a solution to what they term "pedagogic frailty" or the current approach taken in the classroom by the instructor is done on the basis of "it works for me" [20] (Kinchin et al., 2000, p. 3). Kinchin and colleagues find that concept mapping is an approach which can enhance concept learning also note that concept mapping Harrison and Gibbons [21] say concept mapping is "a useful pedagogic tool for teachers and learners". Clayton [22] writes, "In 1997, Ali and Havens [23] defined concept mapping as a pictorial arrangement of key concepts that are unique to a specific subject. All of these researchers follow the basic arrangements of concept mapping used by Trochim and Woelfel and Fink: brainstorming, sorting complex ideas, and pictorial representations. According to Novak and Wandersee [24], concept maps used in teaching promote sense making for students. The intention of the research described below is to use a DME concept map to illustrate how such a map can advance the teaching of a complex subject such as public administration.

\section{Research}

The DME concept mapping project reported here began with "brainstorming" for creating open ended questions to inquire among those typical of the population of students to whom an introductory public administration course was to be delivered. Brainstorming was conducted with suggestions coming from faculty, support staff, and also a graduate student interested in the project at a private higher education institution in New England. The brainstorming produced 4 questions intended to elicit statements or phrases from those who were questioned. The questions include the following:

1. What comes to mind when you hear the term public administration? ...Please, tell me more.

2. What comes to mind when you hear the term government? ...Please, tell me more.

3. What do you think about educating people for government work called public administration? ...Please, tell me more.

4. What do you think people who work for government need to know? ...Please, tell me more.

Human Subjects Review Board approval was obtained in order to allow the research effort. One Hundred voting age persons were chosen on a purposive sample basis using a convenience selection procedure.

1. The population chosen was represented of the community from which students are drawn

2. The program in public administration includes both an undergraduate and graduate program. Thus, students are out of high school, may have community college or military education experience, and most are working

3. The semesters courses had ended by the time the research began

4. Since the map was to inform an introductory course, the cognitive loads of respondents was likely to be that of an entering student rather than current students who had been exposed to public administration history, development, and key women and men

Each interview took approximately 10 minutes and a transcription of answer was created in WORD. The WORD transcription was then submitted to specialized software analysis seeking to find patterns of concepts in all of the answers and across all the answers. The resulting concepts were then placed in a distance magnitude estimation instrument. The concepts which emerged from the analysis of verbal responses were the following: Government, People, Education, Work, State, Officials, Services, and Administration

Even though the term public administration had been used in the open ended questions, the term with its two word concept does not appear in the resulting concept list. This result may be indicative of the cognitive load of an entering student.

The concepts or attributes were used to have the software create a distance magnitude estimation instrument, each term paired with each of the others. Then the terms were placed in comparison to the "yourself" concept. A sample of the paired comparison format is shown in Figure 1 below. It should be added that the concept pairs were also based on a hierarchal ordering as Trochim indicated was necessary. The hierarchal ordering was illustrated in a series of dentograms generated by the software analysis. 
Government and Public

Government and People

Government and Education

Government and Work

Government and State

Government and Officials

Government and Services

Government and Administration

Government and Yourself

Figure 1. Paired comparison sample.

The questionnaire with all the pairs was to be responded to using a "base pair" to allow respondents to judge the distances between terms in all the pairs. The base pair chosen was formed by the concepts of farming and construction. These concepts were chosen since they represented some considerable conceptual difference, thus distance, meaning the terms were dissimilar. Conceptual distance represents similarity or difference in the concepts presented to respondents. Farming and Construction were considered distant enough to warrant the use of the 100 unit difference between them. It is best to approach DME in this way since polar opposites would create the kind of problems encountered using equal appearing intervals and confound the interpretation of the base pair difference and, therefore, differences between the pairs that follow the base pair.

The instrument was presented with the following written instructions:

Please estimate how different or "far apart" each of the following words or phrases are from each of the others. The more different, or further apart they seem to be, the larger the number you should write. To help you know what size number to write, remember:

Farming and Construction are 100 units apart. If two words or phrases are not different at. all, please write zero (0). If you have no idea, just leave the space blank.

The reference pair is a key component of the DME approach. First, the instructions indicate there is a " 0 " point. Thus establishing a measurement reference point which is critical to any measurement. Second, there is no upper limit. A respondent may select any number between 0 and 100 or beyond once the reference pair is established. Third, a reference point to establish " 0 " is the beginning step to establishing a ratio scale. Physicists, for example, use the earth is the reference point to establish the ratio scale of light years. Moreover, ratio scales would not encounter the same perceptual difficulty as equal appearing interval scales.

Before proceeding further with the data gathering, the respondent was informed the university Human Subjects Review Board had approved the project. Respondents were then asked to sign and date an informed consent form. Those who did not wish to sign were thanked for their time and then another respondent was approached. Some simple additional description of what was being asked for was provided if the instrument seemed new to them. Once the initial unfamiliarity was overcome, respondents completed the distance estimations for all the pairs. A total of 106 units of analysis or respondents cooperated with the terms of informed consent and completed the DME instrument. Of the 106 respondents were $52 \%$ male and $42 \%$ were female. The mean age of the sample was 45.01 years. The completed instruments were then coded for analysis to create the concept map and the mathematical analysis which is part of the procedure on DME data. The resulting concept map appears in Figure 2 below:

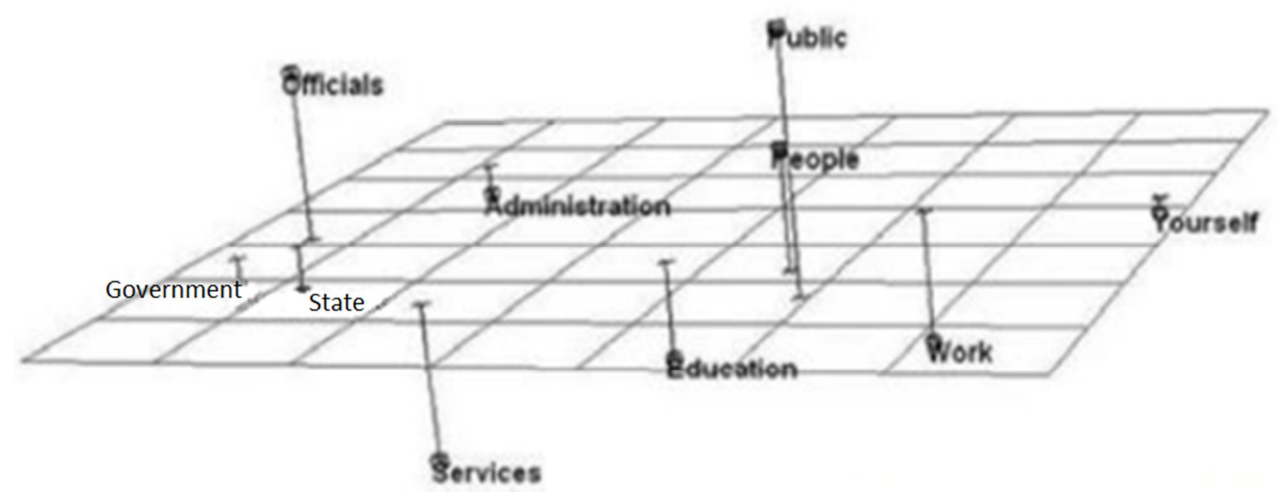

Figure 2. DME concept map.

The map appears in 2 dimensions on the printed page. Nonetheless, the software analysis allows the map to appear in 3 dimensions and can be rotated for somewhat different perspectives. In mathematical terms, the map represents multidimensions; 9 dimensions are present, corresponding the number of concepts in the map. Even if all dimensions were represented, the map would still show the distribution of concepts some considerable distance from "Yourself".
Rotation would not change the distance perspective among and between concepts in the map. The rectangular display of a grid provides the referent space Newcombe discussed. The grid provides a proportional view of how close or distant or different the concepts are. Following Newcombe, viewing map space means appearance of distance translates to perceived distance. Additionally, the spheres representing the location of the concepts are the $95 \%$ Confidence Interval 
meaning the concept shown by the sphere's location is within that sphere. Thus, the placement of the concepts in the map is based on statistical probability indicating the analysis is trustworthy about the placement on the map of the concept. With concepts this far apart in the collective mind of a community, it will take a major creative and analytic effort to craft course presentations. The concepts forming the best course material are presented in order of valence of presentation content are shown in Table 1. As a result of this information, the order needed for appropriate cognitive load and message trajectory are available.

Table 1. Concepts best for course material.

\begin{tabular}{ll}
\hline 1 & Public, Education, and Work \\
2 & People, Education, Work \\
3 & Public, People, Education \\
4 & Education, Work \\
5 & People, Education \\
6 & Public, Education, Officials \\
7 & Public, Education, Administration \\
8 & Public, Education, and State \\
9 & Public, Education, and Services \\
10 & Public, People, and Work \\
\hline
\end{tabular}

This list then is the beginning point for creating or adding to an introductory course in public administration.

\section{Building a Syllabus}

Darn and Gülfem Aslan [25] note that a major factor in student learning is intrinsic motivation, which while challenging to create, can be addressed to an important degree using a key element in the concept map shown above: the self or you. They introduce their approach as establishing flow. Flow is a psychology concept from the work of Csikszentmihaly [26] and represents concentration and motivation. While there are classroom recommendations Darn and Gulem make, the syllabus can be the starting point for flow with the "you" concept in learning outcomes/objectives. Examples are shown below in Exhibit 1.

Exhibit 1 Example Learning Outcomes/Objective

You will learn about, recognize, and understand the Public nature of what governments, nonprofits, and health administration are; the Education required for sound public administration; and the specific Work public administration does.

You will know and understand the People in the community to be served by public administration; the Education citizens need to be partners with public administrator; and the Work required to do so.

These statements are the beginning of flow since they concentrate on what "you" the student will need to concentrate on and what "you" the student are to start forming the intrinsic motivation need to be a learner. The capitalization is intended for emphasis here. Nonetheless, italics, capital letters, or both can serve to focus the students thinking at the beginning of the course.

\section{Lessons}

Would be a logical next step from learning objectives. Naturally, the "you" concept would need to be added to lessons based on the learning objectives. An introduction to the lesson for the first example learning outcome/objective might begin with a statement such as "You are taking part in a course for developing a recognition and understanding about the profession called public administration. The work of governments, nonprofits, and health administration is about managing policy and the programs which make policy effective, you are part of a profession built on the idea that public policy and programs are to create results for citizens. You are urged to join the professional association representing public administration the American Society for Public Administration. All professions are constructed from an education base: lawyers, doctors, engineers, teachers, all begin the careers with education. Education based on course work such as the course you are in now, is deemed to be vital to You being an effective public or health administrator." The lesson can move on to the history of the profession, its contributions, illustrations, or other material the instructor wishes to cover continuing where appropriate the use of "you" and the first set of concepts in the Exhibit 1.

\section{Project Learning}

Zeegers [27] indicates an important part of any course and should be a syllabus "enhancement". Caro, et al., [28] describe a semester long project for a course in a business course. There are several components to the project but among the most usefully transferred to the public administration or any college course are: document their experience of the project which could include a reflection on learning, i.e., what was learned and how the student knows he or she has learned the lesson; define a functional personal meaning for the learning from the project, which would be the "you" concept in a student's learning; identify their strengths weaknesses based on what they have learned, and plan for their future development. They go on to offer measurement of the learning using what they call "measurement". They also note the use of a student portfolio. This latter element is part of many courses, particularly, the Eportfolio required in, but not limited to, undergraduate and graduate courses. The Eportfolio follows the student to include other courses in a curriculum and are used as part of employment applications to demonstrate the skills learned while in the degree program.

While the Caro, et al, example reports on a project outside of the classroom, the project application to a course can also be structured around more traditional class assignments. In public administration a project such as finding museums or hospitals or other public sector organizations for virtual tours. From the virtual tour locations, offices, reception areas, and the like can be examined using in class computers and the internet. This kind of exercise could be potentially a beginning step to understanding what such organizations 
look like and some idea of how they operate, which would be a solid first step in the kind of introductory course which is being explored here.

The personal development plan they suggest a clear indication of using the "you" concept in the learning setting. By focusing on what each student plans to accomplish the student is responsible for translating the course into a self focused individual interpretation of the elements to the concept map shown above.

\section{Student Learning Evaluation}

The concept mapping based course need not eliminate traditional testing or other objective assessments, but since the map and the "you" concept are central to such a course the accent on self with the kinds of assessments Caro, et al., report would be the optimum approach. Thus, using the concept map itself would be advisable. One way to employ the map would be a pretest/posttest Each student could be given a copy of the map at the beginning of the course to depict where he or she believes himself or herself to be on the map. Then at the end of the course the same procedure could be used to determine self or "you" changes. Then pretest map and posttest maps can then be compared and discussed followed by class discussion or put in the Eportfolio reflections.

A second method might be to use the DME questionnaire at the beginning and at the end of the course. Using the DME values a new map could emerge to illustrate movement based on the learning in the course. A third approach could include both the self-reported map and the new DME map.

One other idea for using the map would be to use the Third approach at the beginning of the degree program and then at the end. In this way, faculty and students can examine learning throughout the program and have a record of achievement of learning outcomes for the curriculum as a whole. The information from such an exercise would be extremely valuable for course development, syllabus preparations, project learning assignments, and provide a vehicle for improvement in all these areas which can only benefit the student, particularly, students who will become practitioners as in the case of public administrators.

In their paper on using concept mapping to improve course content Amudsen, et al., [29] report that the concept proved to be a "first step in the course design process" (p. 649). Using concept mapping for that purpose, they note it provided "a means to determine and rethink course content, one that highlighted relationships among concepts, encouraged a view of the course as an integrated whole and frequently provided the occasion to make explicit types the thinking required in the course". It is axiomatic that faculty members no matter the discipline, social science, life sciences, physics, or humanities would like to achieve these kinds of results in their courses.

Amundsen, et al., go on to describe value in reflections on learning based on concept mapping. They note positive results from using the map for such reflection as illustrated in the assessment approaches discussed above. They further report the reflections based on the map they used generated changes in the concept map and the courses which would be applied to it.

\section{Conclusion}

By adapting a concept map of the kind shown here, an instruction can have a valuable tool for navigating individual student learning, student sense making, cognitive load, and then blending the instructor teaching style to these areas. Such a concept map tool would accomplish a sound course design, delivery, and assessment to enhance student learning "take aways" while allowing the instructor to maintain her or his teaching style. It must be further noted that while the example here is public administration, there is no limitation to the disciplines to which the concept course design is limited. All the steps outlined above from brainstorming and sorting to final map can be applied to all kinds of courses.

\section{References}

[1] Luton, Larry S., (2002); "The Tale that Wagged the Dog: is the Progressive Era the Foundation of American Public Administration?" Administrative Theory \& Praxis, 24 (3), (2002): 439.

[2] Durant, Robert F.; Ali, Susanna Burns, "Repositioning American Public Administration? Citizen Estrangement, Administrative Reform, and the Disarticulated State." Public Administration Review, 73 (2), (2013): 278-289.

[3] Gallagher, James J., (2015); "Teacher Variation in Concept Presentation in BSCS Curriculum Program", Journal for the Education of the Gifted, 38 (1): 24-43.

[4] Hayne, Arlene M. and McDaniel, Gretchen S. (2013), "Presentation Rubric: Improving Faculty Professional Presentations", Nursing Forum, 48 (4): 289-294.

[5] Jornet, Alfred; Roth, Wolff-Michael, (2015); “The Joint Work of Connecting Multiple (Re) Presentations in Science Classrooms", Science Education. Mar2015, Vol. 99 (2): 378403.

[6] Bulunuz, Nermin and Jarret, Olga S.; (2009); “Understanding of Earth and Space Science Concepts: Strategies for ConceptBuilding in Elementary Teacher Preparation", School Science \& Mathematics, 109 (5): 276-289.

[7] Lee, Sungkyoung; Lang, Annie, "Redefining Media Content and Structure in Terms of Available Resources: Toward a Dynamic Human-Centric Theory of Communication." Communication Research, 42 (5), (2015): 599-625.

[8] Chung, Sungeon; Fink, Edward, L. (2008); "The Cognitive Dynamics of Belief: The Effect of Information on Message Processing”, Human Communication Research, 34, (3): 477504.

[9] Niederdeppe, Jeff; Bu, Q L.; Borah, Porismita; Kindig, David A.; Robert, Stephanie A., "Message Design Strategies to Raise Public Awareness of Social Determinants of Health and Population Health Disparities," Milbank Quarterly, 86 (3), (2008):481-513. 
[10] Trochim, William K.; Cook, Judith A., and Seize, Rose J., (1994); "Using Concept Mapping to Develop a Conceptual Framework of Staff's Views of a Supported Employment Program for Individuals with Severe Mental Illness", Journal of Consulting and Clinical Psychology, 62 (4): 766-775.

[11] Freeman, L. A., \& Jessup, L. M. (2004). "The Power and Benefits of Concept Mapping: Measuring Use, Usefulness, Ease of Use, and Satisfaction". International Journal of Science Education, 26, 151-169.

[12] Woelfel, Joseph and Fink, Edward, The Measurement of Communication Processes: Galileo Theory and Method. New York: Academic Press, 1980.

[13] Hall, Michael, "Nonprofit Health Care Services: Persuasive Messages Based on Multidimensional Concept Mapping and Direct Magnitude Estimation.” Health Marketing Quarterly, July-September, 26 (3), (2009):165-182.

[14] Newcombe, Nora S., "The Origins and Development of Magnitude Estimation", Ecological Psychology, 26 (1-2), (2014):147-157.

[15] Eadie, Tanya L.; Doyle, Philip C., "Direct Magnitude Estimation and Interval Scaling of Naturalness and Severity in Tracheoesophageal (TE) Speakers." Journal of Speech, Language \& Hearing Research, 45 (6), (2002): 1088.

[16] Stevens, S. S. (1974). Perceptual magnitude and its measurement. In E. C. Caterette \& M. P. Friedman (Eds.), Handbook of Perception 2:22-40. New York: Academic Press.

[17] Aydogan, Tuncay and Ergun, Serap, (2016); “A Study to Determine the Contribution made by Concept Maps to a Computer Architecture and Organization Course", European Journal of Contemporary Education, 15 (1): 76-83.

[18] Ali, Maznah and Ismail, Zurida. (2005); Journal of Science and Mathematics Education in S.E. Asia, 28 (1): 43-55.

[19] Novak, J. D \& Gowin, D. B. (1984). Learning How to Learn. New York: Cambridge University Press.
[20] Kinchin, I. M.; Alpay, E.; Franklin, J.; Rivers, C.; and Winstone, N.E., (2016); "Charting the elements of pedagogic frailty", Educational Research, 58 (1): 1-23.

[21] Harrison, Suzanne and Gibbons, Caroline, (2013): "nursing student perceptions of concept maps: from theory to practice", Nursing Education Perspectives, 34 (6): 395-399.

[22] Clayton, Laura H. (2006); "Concept Mapping: An Effective, Active Teaching-Learning Method", Nursing Education, 27 (4): 197-203.

[23] All, A.C., \& Havens, R.L. (1997). "Cognitive/concept mapping: A teaching strategy for nursing", Journal of Advanced Nursing, 25, 1210-1219.

[24] Novak, J. D., \& Wandersee, J. (1991). Special Issue on Concept Mapping. Journal of Research in Science Teaching, 28,10 .

[25] Darn, Steve; Aslan, Gulfem; (2006), "Strategies for Efficient Use of Teaching Time”, Online Submission, (ED493708).

[26] Csikszentmihalyi, Mihaly; (1990), Flow: The Psychology of Optimal Experience, Harper Collins, 1990.

[27] Zeegers, Yvonne (2012); "Curriculum Development for Teacher Education in the Southern Philippines: A Simultaneous Process of Professional Learning and Syllabus Enhancement"; International Journal Education Development"; 32 pp. 207-2013.

[28] Caro, Cary A.; Lirette, Kolby; Yest, Myke; (2013); "Redesigning MGMT 4010S: Creating A Cause of Social Responsibility and Social Justice"; American Journal of Business Education; 6:2; 155-159.

[29] Amundsen, Cheryl; Weston, Cynthia; McAlpine; (2008); "Concept mapping to support university academics' analysis of course content"; Studies in Higher Education; 33: 6; 633352. 